\title{
New developments in the treatment of peripheral T-cell lymphoma - role of Belinostat
}

This article was published in the following Dove Press journal:

Cancer Management and Research

3 June 2015

Number of times this article has been viewed

\section{Peter Reimer \\ Clinic for Hematology, Medical \\ Oncology and Stem Cell \\ Transplantation, Evangelisches \\ Krankenhaus Essen-Werden gGmbH, \\ Essen, Germany}

Correspondence: Peter Reimer

Clinic for Hematology, Medical

Oncology and Stem Cell Transplantation,

Evangelisches Krankenhaus Essen-

Werden gGmbH, Pattbergstr. I-3,

45239 Essen, Germany

Tel +49 20I 40892230

Fax +49 20I 40892297

Email p.reimer@kliniken-essen-sued.de
Abstract: Peripheral T-cell lymphomas (PTCL) represent a heterogeneous group of rare malignancies that with the exception of anaplastic lymphoma kinase expressing anaplastic large cell lymphoma, share a poor outcome after standard (eg, anthracycline-based) chemotherapy. Most patients are either refractory to initial therapy or eventually relapse. Randomized studies for relapsed/refractory PTCL are not available, however, recently published data show that conventional chemotherapy has very limited efficacy in the salvage setting. Thus, novel drugs are urgently needed to improve the outcome in this setting. Belinostat, a pan-histone deacetylase inhibitor, has demonstrated meaningful efficacy and a favorable toxicity profile in two single-arm Phase II trials on 153 patients with relapsed/refractory PTCL. The conclusive results led to an accelerated approval by the US Food and Drug Administration. The present review summarizes the clinical data available for belinostat, its current role, and future perspectives.

Keywords: T-cell lymphoma, relapsed/refractory, treatment, belinostat

\section{Introduction}

Peripheral T-cell lymphomas (PTCL) are a rare and heterogeneous group of nonHodgkin's lymphomas (NHL) deriving from mature, post-thymic T- and natural killer (NK-) cells. PTCL count for approximately 10\% of all NHL in Europe and North America, ${ }^{1-3}$ but present with a higher incidence in East Asia and the Caribbean, especially with respect to Epstein-Barr virus and human T-cell leukemia virus type-I associated entities. ${ }^{46}$ In contrast to B-cell NHL that are mainly classified into indolent and aggressive subtypes. PTCL are further subdivided primarily according to their site of manifestation. With regard to the current WHO classification, leukemic, cutaneous, nodal, and extranodal PTCL are distinguished. ${ }^{6}$ In general, cutaneous and leukemic entities show an indolent clinical course and are separated from the nodal and extranodal subtypes. Therefore, following a commonly used closer definition of PTCL, also used in this review, PTCL only include nodal and extranodal PTCL. The most frequent entities are PTCL not otherwise specified (PTCL, NOS), angioimmunoblastic T-cell lymphoma (AITL), and anaplastic large cell lymphoma (ALCL) with or without expression of the anaplastic lymphoma kinase (ALK). ${ }^{7}$

Apart from ALK-positive ALCL, PTCL have a poor clinical outcome. ${ }^{7-13}$ To date, due to the rare incidence and the lack of randomized clinical Phase III trials, there is no consensus on standard therapy either in the upfront setting or for refractory or relapsed (R/R) PTCL. As first-line therapy, anthracycline-based conventional (CHOP-like) multi-agent chemotherapy protocols are most commonly used. However, with this approach, long-term remissions are achieved only in a 
minority of patients, resulting in a median overall survival (OS) of 9 to 42 months. ${ }^{14-16}$ Several prospective series have shown promising results for a consolidation treatment using myeloablative therapy with autologous stem cell transplantation (autoSCT) in patients responding to induction chemotherapy. ${ }^{17-21}$ Therefore, this approach is recommended in many centers; however, randomized data are not available yet.

Salvage treatment for PTCL is often required because most patients have refractory disease or eventually relapse. Several strategies have been investigated to improve the prognosis of patients with R/R PTCL. However, the data are sparse and available studies lack a randomized control arm. In a recently published retrospective analysis Mak et al could demonstrate that conventional chemotherapy does not impact on OS in R/R PTCL and seems not to be superior to best supportive care alone. ${ }^{22}$ On the other hand, several series on allogeneic stem cell transplantation (alloSCT) can lead to long-term disease-free survival in a subgroup of patients. ${ }^{23-31}$ However, most of the data on alloSCT are retrospective, and consequently, the results are biased by patient selection. Moreover, this approach is associated with a substantial treatment-related morbidity and mortality and is limited to eligible patients. Therefore, with respect to the median age of patients with PTCL, that is, above 60 years, many patients are not candidates for even dose-reduced conditioning regimen-based alloSCT. In summary, since conventional treatment strategies alone seem to have limited efficacy or are restricted only to subsets of patients, novel targeted agents with a more specific mechanism of action are urgently needed. Following decades without any noteworthy progress in the treatment of R/R PTCL, four drugs have been approved worldwide for the treatment of $\mathrm{R} / \mathrm{R}$ noncutaneous PTCL in the last 6 years. Pralatrexate, an antifolate, and romidepsin, a histone deacetylase inhibitor (HDACi), have shown significant efficacy in R/R PTCL, and have therefore been approved by the United States Food and Drug Administration (FDA) in 2009 and 2011, respectively. ${ }^{32-34}$ Brentuximab vedotin, a CD30-targeted immunoconjugate, has shown a high response rate of $85 \%$ in a Phase II study of 58 patients with CD30+ ALCL who had experienced at least one prior therapy. ${ }^{35}$ For R/R ALCL, expressing the CD30 antigen Brentuximab vedotin was approved by the FDA and the European Medicines Agency (EMA) in 2011 and 2012, respectively. Recently, belinostat, another HDACi, was approved by the FDA in 2014. This review focuses on belinostat, its current impact on treatment algorithm and its future perspective.

\section{Mechanism of action and pharmacokinetics}

Histones are proteins that compact DNA in the cell nucleus and are modified by acetylation, methylation, or phosphorylation. Histone deacetylases (HDAC) are a class of enzymes that allow tight DNA wrapping by removing acetyl groups from an $\varepsilon-\mathrm{N}$-acetyl lysine amino acid on a histone, and thereby regulate DNA expression. To date, four classes of HDAC are known. Unlike other HDACi, belinostat, a hydroxamic acid-derived pan-HDACi, targets class I, II, and IV HDAC, showing antitumor and antiangiogenic properties in a wide range of cancer cell lines with sub to low micromolar potency in vitro. ${ }^{36}$ In general, HDACi targets the HDAC, thereby increasing acetylation of different substrates in the nucleus. However, so far, the exact mechanism of action of HDACi in PTCL is unknown. Available data suggest that acetylation of histones in malignant cells is often deranged. This could lead to alterations in gene expression effecting cell growth, cell cycle arrest, cell differentiation, and programmed cell death (apoptosis) that can be reconstituted by HDACi. ${ }^{37}$ Furthermore, deacetylation of histones can lead to silencing of tumor suppressor genes. ${ }^{38}$ Therefore, HDACi might re-express epigenetically silenced tumor suppressor genes and have the potential to reactivate the innate tumor control.

The pharmacokinetics data of belinostat have been initially investigated after intravenous or oral administration in rats and dogs. The drug showed two-compartment kinetics with rapid distribution and an elimination half-life of 1-2 hours. After oral absorption, the bioavailability was about $30 \%$ in dogs. Following rapid metabolism to several metabolites, main excretion of belinostat was via the bile and/or feces. ${ }^{39} \mathrm{In}$ a pharmacokinetics and pharmacodynamics study in patients with solid tumors belinostat displays three-compartment pharmacokinetics with an elimination half-life ranging from 0.3 to 1.3 hours independent of dose. With regard to area under the curve (AUC) and $C_{\max }$, the drug showed linear (dose-proportional) pharmacokinetics without any relevant drug accumulation. The excreted parent drug in urine did not exceed $2 \%$. The pharmacodynamics studies revealed a definite increase in histone $\mathrm{H} 4$ acetylation at the end of infusion at all doses. At doses $>150 \mathrm{mg} / \mathrm{m}^{2}$, the increased $\mathrm{H} 4$ acetylation was sustained and persists above baseline levels up to 24 hours after the end of infusion. Furthermore, the authors 
revealed a dose-related increase in histone $\mathrm{H} 4$ acetylation AUC up to approximately $900 \mathrm{mg} / \mathrm{m}^{2}{ }^{40}$

\section{Clinical efficacy - Phase I studies}

Belinostat was first investigated in several Phase I trials to determine the maximum tolerated dose (MTD). ${ }^{40-42}$ In the study by Steele et al, in 46 patients with advanced solid tumors, the intravenously given dose ranged from $150 \mathrm{mg} / \mathrm{m}^{2}$ to $1,200 \mathrm{mg} / \mathrm{m}^{2}$. During this dose-escalating phase, doselimiting toxicities developed at a dose of $600 \mathrm{mg} / \mathrm{m}^{2}$ in one patient and at a dose of $1,200 \mathrm{mg} / \mathrm{m}^{2}$ in three patients. After continuing the study at a dose level of $1,000 \mathrm{mg} / \mathrm{m}^{2}$ without dose-limiting toxicities in all six patients, an additional 18 patients were treated at this dose level. Given the results of preliminary studies on pharmacokinetics and pharmacodynamics and the observed toxicities, the MTD was determined to be $1,000 \mathrm{mg} / \mathrm{m}^{2}$ on days 1 to 5 of every 3 -week cycle. Doselimiting toxicities were fatigue, diarrhea, nausea, emesis, and atrial defibrillation. ${ }^{40}$ In another Phase I study in 16 patients with advanced hematologic malignancies, a similar dose of $1,000 \mathrm{mg} / \mathrm{m}^{2}$ in the same schedule was recommended for future Phase II studies. The most common treatment-related adverse events of all grades were nausea, vomiting, fatigue, and flushing. Besides one case of grade 3 lymphopenia, no grade 3 or 4 hematological toxicity was observed. Two treatment-related grade 4 adverse events of renal failure occurred in two patients with multiple myeloma. ${ }^{41}$ In the Phase I study by Lassen et al, belinostat was investigated in combination with carboplatin and paclitaxel in 23 patients with solid tumors. Again 1,000 mg/m² day 1-5 was considered the optimal dose for belinostat. Grade 3/4 adverse events included leucopenia, neutropenia, thrombocytopenia, anemia, peripheral sensory neuropathy, fatigue, vomiting, and myalgia. Importantly, the pharmacokinetics of belinostat, paclitaxel, and carboplatin were not altered by the concurrent administration. ${ }^{41}$ Oral administration of belinostat has also been evaluated using different regimen in advanced solid tumors and hematologic malignancies. ${ }^{43-45}$ However, taking together the available data, the optimal dosing and scheduling of oral belinostat have not been established yet.

\section{Clinical efficacy - Phase II studies}

In the first published Phase II study on belinostat in the treatment of patients with T-cell lymphoma, Foss et al evaluated safety and efficacy in 53 patients with cutaneous T-cell lymphoma ( $\mathrm{n}=29)$ and PTCL $(\mathrm{n}=24)$. This was an open label, international multicenter study conducted in 15 institutions in five countries. The subgroup of patients with PTCL was heavily pretreated and received a median of three prior systemic therapies. Five patients had undergone autoSCT. Patients who had received alloSCT were excluded from the study. The PTCL cohort had a median age of 64 years, with a male predominance of $71 \%$. Most subtypes were PTCL, $\operatorname{NOS}(n=13,54 \%), \operatorname{ALCL}(n=3,13 \%)$, and AITL $(n=3,13 \%)$. Belinostat was given as a 30 -minute infusion of $1,000 \mathrm{mg} / \mathrm{m}^{2}$ on days 1 to 5 of a 3 -week cycle. A dose escalation to $1,200 \mathrm{mg} /{ }^{2}$ for cycle 2 and $1,400 \mathrm{mg}^{2}$ for cycle 3 was permitted in the absence of grade $\geq 2$ treatment-related adverse events. Responding patients who achieved a partial remission (PR) or a stabilization of the disease after cycle 2 were allowed to receive six additional courses or could continue belinostat therapy until disease progression. Patients obtaining a complete remission (CR) were eligible for retreatment at the time of progression at the investigators' discretion. The primary endpoint of the trial was overall response rate (ORR). Secondary endpoints were duration of response, time to response, time to progression and safety. For the PTCL group, ORR was $25 \%$ including two complete and four PRs. In four patients (17\%), stable disease could be achieved. The time to response ranged from 33 days to 431 days, the median duration of response was 109 days, and the median time to progression was 82 days. ${ }^{46}$

Final results from the much larger BELIEF trial, a Phase II study on 129 patients with R/R PTCL were presented by O'Connor at the ASCO meeting 2013. ${ }^{47}$ Patients, who had failed at least one prior therapy, were enrolled in this singlearm study at 62 sites in North America, Europe, and Africa. Diagnosis was confirmed by central pathology review (CPR). Further inclusion criteria included measurable lymphoma manifestation, thrombocyte counts of $\geq 50,000 / \mu \mathrm{L}$, absence of prior HDACi therapy, adequate organ function, and no relapse following autoSCT or alloSCT within 100 days. The primary endpoint was ORR, as assessed by an independent review committee. Secondary endpoints were safety, OS, progression-free survival (PFS), duration of response, time to response, time to progression, 1-year progression-free rate, and 1-year survival rate.

The number of cycles administered was not restricted. Patients were treated until disease progression, unmanageable toxicity, death, or successful bridging to stem cell transplantation. Diagnosis of PTCL was confirmed by CPR in 120 out of 129 patients. Most patients suffered from PTCL, NOS $(n=77,64 \%)$. The remaining subtypes included AITL $(n=22,18 \%)$, ALCL $(n=15,13 \%)$, and others $(n=6$, 
$6 \%$ ). The median age was 63 years (range, 29-81 years). The median number of prior treatment lines was 2 (range, 1-8). Previous CHOP/CHOP-like regimen had been given to 125 patients $(96 \%)$. A total of 27 patients $(21 \%)$ had undergone prior autoSCT and two patients $(2 \%)$ had had an alloSCT. The median time from first diagnosis to study entry was 12 months and the median time from last disease progression to study entry was 1 month. Bone marrow involvement was seen in $30 \%$ of patients. The median number of cycles administered was two, and the median duration of treatment was 7 weeks. The main reasons for treatment discontinuation were progressive disease $(n=82)$, death $(n=14)$, patient decision $(n=11)$, and adverse events $(n=9)$. A total of 17 patients (13\%) required dose reduction mainly to the first level of dose reduction $\left(750 \mathrm{mg} / \mathrm{m}^{2}\right)$.

In terms of efficacy, 13 patients $(11 \%)$ achieved a CR, 18 patients demonstrated a PR (15\%), resulting in an ORR of $26 \%$. In responding patients, the median time to response was 5.6 weeks (range, 4.3-50.4 weeks). The median duration of response was 13.6 months (range, 4.529.4 months). The median PFS and OS were 1.6 months and 7.9 months, respectively. Importantly, nine patients $(7.5 \%)$ were able to proceed to stem cell transplantation. For the subgroup of patients $(n=20)$ with a thrombocyte count $<100,000 / \mu \mathrm{L}$, ORR, duration of response, median PFS, OS, and time to response were considerably worse compared with patients presenting with a baseline platelet count $\geq 100,000 / \mu \mathrm{L}$. In a subgroup analysis presented at the International Conference on Malignant Lymphoma in Lugano in 2013, belinostat treatment resulted in a favorable $45 \%$ response rate among the subgroup of 22 patients with R/R AITL. This resulted in a median PFS and OS for this cohort of 5.8 and 9.2, respectively, which seems to be somewhat superior to the results for the entire PTCL group. Table 1 summarizes the efficacy data of the two Phase II studies on belinostat. ${ }^{48}$

Table I Efficacy data for belinostat from Phase II studies

\begin{tabular}{lll}
\hline & Foss $^{46}$ & O'Connor $^{47}$ \\
\hline Patients with PTCL & 24 & 120 \\
ORR (\%) & $25 \%$ & $26 \%$ \\
CR/PR (\%) & $8 \% / 17 \%$ & $11 \% / 15 \%$ \\
Median OS & nd & 7.9 months \\
Median PFS & nd & 1.6 months \\
Time to response & nd & 5.6 weeks \\
Duration of response & 109 days & 13.6 months \\
Time to progression & 82 days & nd \\
\hline
\end{tabular}

Abbreviations: CR, complete remission; nd, no data; ORR, overall response rate; $\mathrm{OS}$, overall survival; PR, partial remission; PFS, progression-free survival; PTCL, peripheral T-cell lymphomas.
Recently, a case report was published documenting high efficacy of belinostat in an elderly female patient with PTCLNOS. ${ }^{49}$ After failing three different chemotherapy regimens, the patient was treated with belinostat and achieved a CR after two cycles. The patient received a total of 28 cycles and maintained a CR for 46 months. The patient relapsed 15 months after the last application of belinostat and died 3 months later due to progressive disease (personal communication).

\section{Safety}

In the Phase II study by Foss et al, 23 treatment-emerged adverse events of all grades were documented in $77 \%$ of all patients. These included nausea (67\%), constipation $(38 \%)$, and vomiting (25\%) with the highest incidence. For the PTCL cohort, five grade-3 nonhematologic events (pneumonitis, paralytic ileus, cellulitis, and two cases of rash) and one grade-4 event (thrombocytopenia) were reported. A total of seven patients experienced serious adverse events. One patient with a history of left anterior hemiblock died of ventricular fibrillation 6 days after the last dose of belinostat in cycle 2. However, after assessment of the pre- and poststudy ECGs by an independent cardiology review, the fatal arrhythmia was determined unlikely to be related to belinostat exposure. Hematologic toxicities grades 3 and 4 were seen in 15 patients (63\%) with PTCL. The most frequent abnormality was lymphopenia $(n=15,63 \%)$. Three patients discontinued treatment due to therapy-emerged adverse events.

In the BELIEF trial, hematologic toxicity of grade 3/4 was seen in $12 \%$ of the patients for anemia, $13 \%$ for leukopenia, and $15 \%$ for thrombocytopenia. Grade 3/4 nonhematologic treatment-emerged adverse events were rare. Most reported adverse events included dyspnea (6\%), pneumonia (5\%), febrile neutropenia $(5 \%)$, and fatigue $(5 \%)$. Nine patients discontinued therapy due to adverse events. Overall, belinostat was well tolerated and demonstrated a favorable safety profile.

\section{Summary and future perspectives}

To date, there is no standard approach for PTCL in the salvage setting. Conventional chemotherapy has very limited value and only a minority of patients is eligible to undergo (allo) stem cell transplantation. Therefore, novel drugs are urgently needed. Belinostat, a pan-HDACi, has shown conclusive efficacy in two Phase II trials. The ORR of $26 \%$ demonstrated in the BELIEF trial combined with the good safety profile led to an accelerated approval of belinostat for R/R PTCL by the FDA in July 2014. Belinostat has been incorporated in the guidelines of the National Comprehensive Cancer 
Table 2 Comparison of novel agents approved for R/R PTCL

\begin{tabular}{|c|c|c|c|c|}
\hline & Belinostat $^{46}$ & Romidepsin ${ }^{33}$ & Pralatrexate $^{32}$ & Brentuximab $^{35}$ \\
\hline Phase II study (n) & 120 & 130 & 109 & 58 \\
\hline ORR & $26 \%$ & $25 \%$ & $29 \%$ & $86 \%$ \\
\hline CR/PR & $11 \% / 15 \%$ & $15 \% / 10 \%$ & $11 \% / 18 \%$ & $57 \% / 29 \%$ \\
\hline Median OS & 7.9 months & II.3 months & I 4.5 months & Not reached \\
\hline Median PFS & 1.6 months & 4 months & 3.5 months & I 3.3 months \\
\hline Time to response & 5.6 weeks & I.8 months & nd & 5.9 weeks \\
\hline Duration of response & 13.6 months & $17 / 28$ months & 10.1 months & 12.6 months \\
\hline Bridging to SCT & $8 \%$ & nd & $7 \%$ & $28 \%$ \\
\hline Main toxicities Grade 3/4 & $\begin{array}{l}\text { Thrombocytopenia } \\
\text { anemia, leukopenia }\end{array}$ & $\begin{array}{l}\text { Thrombocytopenia } \\
\text { neutropenia, infections }\end{array}$ & $\begin{array}{l}\text { Thrombocytopenia, mucositis, } \\
\text { leukopenia, anemia }\end{array}$ & $\begin{array}{l}\text { Neutropenia, } \\
\text { thrombocytopenia neuropathy }\end{array}$ \\
\hline
\end{tabular}

Abbreviations: ALCL, anaplastic large cell lymphoma; CR, complete remission; nd, no data; ORR, overall response rate; OS, overall survival; PR, partial remission; SCT, stem cell transplantation; PTCL, peripheral T-cell lymphomas; R/R, relapsed and refractory.

Network as salvage therapy for patients with R/R PTCL. The response rate of belinostat in the cited studies is in the range of that reported for romidepsin and pralatrexate, but the toxicity profiles of the three drugs differ. To date, given the limited data, a clear advantage of one drug over the other cannot be seen. Decision making in favor of one of the drugs should be made on an individual basis, especially considering the differing toxicity profiles. In addition, belinostat may be considered to serve as bridging therapy to achieve a remission prior to potentially definite stem cell transplantation. Table 2 summarizes the clinical data of all four FDA-approved drugs for R/R PTCL.

Due to its favorable safety profile and proven efficacy, belinostat seems a very attractive candidate for combination therapies. A Phase I clinical trial in combination with CHOP chemotherapy has been initiated in newly diagnosed PTCL (NCT01839097). This approach might lead to a randomized Phase III study in the future comparing this combination therapy with standard CHOP therapy in the upfront setting. In addition, belinostat is under investigation in combination strategies and is being evaluated as an oral formulation for solid tumors.

\section{Disclosure}

The author has no relevant affiliations or financial involvement with any organization or entity with a financial interest in or financial conflict with the subject matter or materials discussed in the manuscript. This includes employment, consultancies, honoraria, stock ownership or options, expert testimony, grants or patents received or pending, or royalties. The author reports no conflicts of interest in this work.

\section{References}

1. Ascani S, Zinzani PL, Gherlinzoni F, et al. Peripheral T-cell lymphomas. Clinico-pathologic study of 168 cases diagnosed according to the REAL classification. Ann Oncol. 1997;8(6):583-592.
2. [No authors listed]. A clinical evaluation of the International Lymphoma Study Group classification of non-Hodgkin's lymphoma. The Non-Hodgkin's Lymphoma Classification Project. Blood. 1997;89(11): 3909-3918.

3. Rüdiger T, Weisenburger DD, Anderson JR, et al; Non-Hodgkin's Lymphoma Classification Project. Peripheral T-cell lymphoma (excluding anaplastic large-cell lymphoma): results from the NonHodgkin's Lymphoma Classification Project. Ann Oncol. 2002;13(1): 140-149.

4. Swerdlow SH, Habeshaw JA, Rohatiner AZ, Lister TA, Stansfeld AG. Caribbean T-cell lymphoma/leukemia. Cancer. 1984;54(4):687-696.

5. Nakamura S, Suchi T, Koshikawa T, et al. Clinicopathologic study of 212 cases of peripheral T-cell lymphoma among the Japanese. Cancer. 1993;72(5):1762-1772.

6. Catovsky D, Müller-Hermelink HK, Ralfkiaer E, et al. Mature T-cell and NK-cell neoplasms. In: Swerdlow SH, Campo E, Harris NL, editors. World Health Organization Classification of Haematopoietic and Lymphoid Tissues. 4th ed. Lyon: IARC; 2008:269-319.

7. Armitage J, Vose JM, Weisenburger D. International peripheral T-cell and natural killer/T-cell lymphoma study: pathology findings and clinical outcomes. J Clin Oncol. 2008;26(25):4124-4130.

8. Armitage JO, Vose JM, Linder J, et al. Clinical significance of immunophenotype in diffuse aggressive non-Hodgkin's lymphoma. J Clin Oncol. 1989;7(12):1783-1790.

9. Gisselbrecht C, Gaulard P, Lepage E, et al. Prognostic significance of T-cell phenotype in aggressive non-Hodgkin's lymphomas. Groupe d'Etudes des Lymphomes de l'Adulte (GELA). Blood. 1998;92(1): $76-82$.

10. Melnyk A, Rodriguez A, Pugh WC, Cabannillas F. Evaluation of the revised European-American lymphoma classification confirms the clinical relevance of immunophenotype in 560 cases of aggressive non-Hodgkin's lymphoma. Blood. 1997;89(12):4514-4520.

11. Gascoyne RD, Aoun P, Wu D, et al. Prognostic significance of anaplastic lymphoma kinase (ALK) protein expression in adults with anaplastic large cell lymphoma. Blood. 1999;93(11):3913-3921.

12. Falini B, Pileri S, Zinzani PL, et al. ALK+ lymphoma: clinico-pathological findings and outcome. Blood. 1999;93(8):2697-2706.

13. Coiffier B, Brousse N, Peuchmaur M, et al. Peripheral T-cell lymphomas have a worse prognosis than B-cell lymphomas: a prospective study of 361 immunophenotyped patients treated with the LNH-84 regimen. The GELA (Groupe d'Etude des Lymphomes Agressives). Ann Oncol. 1990;1(1):45-50.

14. Huang HQ, Peng YL, Lin XB, et al. Clinical outcomes of 106 patients with peripheral T-cell lymphoma treated by standard CHOP regimen [abstract]. Ai Zheng. 2004;23(Suppl 11):S1443.

15. Kim K, Kim WS, Jung CW, et al. Clinical features of peripheral T-cell lymphomas in 78 patients diagnosed according to the Revised European-American lymphoma (REAL) classification. Eur J Cancer. 2002;38(1):75-81 
16. López-Guillermo A, Cid J, Salar A, et al. Peripheral T-cell lymphomas: initial features, natural history, and prognostic factors in a series of 174 patients diagnosed according to the REAL classification. Ann Oncol. 1998;9(8):849-855.

17. Corradini P, Tarella C, Zallio F, et al. Long-term follow-up of patients with peripheral T-cell lymphomas treated up-front with high-dose chemotherapy followed by autologous stem cell transplantation. Leukemia. 2006;20:1533-1538.

18. Rodríguez J, Conde E, Gutiérrez A, et al; 'Grupo Español de Linfomas/ Trasplante Autólogo de Médula Osea' (GEL-TAMO). Frontline autologous stem cell transplantation in high-risk peripheral T-cell lymphoma: a prospective study from The Gel-Tamo Study Group. Eur J Haematol. 2007;79:32-38.

19. Mercadal S, Briones J, Xicoy B, et al; Grup per l'Estudi dels Limfomes de Catalunya I Balears (GELCAB). Intensive chemotherapy (high-dose CHOP/ESHAP regimen) followed by autologous stem-cell transplantation in previously untreated patients with in peripheral T-cell lymphoma. Ann Oncol. 2008; 19:958-963.

20. Reimer P, Rüdiger T, Geissinger E, et al. Autologous stem cell transplantation (autoSCT) as first-line therapy in peripheral $\mathrm{T}$ cell lymphomas (PTCL). Results of a prospective multicenter study. J Clin Oncol. 2009;27:106-113.

21. d'Amore F, Relander T, Lauritzsen GF, et al. Up-front autologous stemcell transplantation in peripheral T-cell lymphoma: NLG-T-01. J Clin Oncol. 2012;30:3093-3099.

22. Mak V, Hamm J, Chhanabhai M, et al. Survival of patients with peripheral T-cell lymphoma after first relapse or progression: spectrum of disease and rare long-term survivors. J Clin Oncol. 2013;31(16): 1970-1976.

23. Murashige N, Kami M, Kishi Y, et al. Allogeneic haematopoietic stem cell transplantation as a promising treatment for natural killer-cell neoplasms. Br J Haematol. 2005;130(4):561-567.

24. Le Gouill S, Milpied N, Buzyn A, et al; Société Française de Greffe de Moëlle et de Thérapie Cellulaire. Graft-versus-lymphoma effect for aggressive T-cell lymphoma in adults: a study by the Société Française de Greffe de Moëlle et de Thérapie Cellulaire. J Clin Oncol. 2008;26(14):2264-2271.

25. Kyriakou C, Canals C, Finke J, et al. Allogeneic stem cell transplantation is able to induce long-term remissions in angioimmunoblastic T-cell lymphoma: a retrospective study from the lymphoma working party of the European group for blood marrow transplantation. J Clin Oncol. 2009;27(24):3951-3958.

26. Jacobsen ED, Kim HT, Ho VT, et al. A large single-center experience with allogeneic stem-cell transplantation for peripheral T-cell nonHodgkin lymphoma and advanced mycosis fungoides/Sezary syndrome. Ann Oncol. 2011;22(7):1608-1613.

27. Delioukina M, Zain J, Palmer JM, Tsai N, Thomas S, Forman S. Reduced-intensity allogeneic hematopoietic cell transplantation using fludarabine-melphalan conditioning for treatment of mature T-cell lymphomas. Bone Marrow Transplant. 2012;47(1):65-72.

28. Dodero A, Spina F, Narni F, et al. Allogeneic transplantation following a reduced-intensity conditioning regimen in relapsed/refractory peripheral T-cell lymphomas: long-term remissions and response to donor lymphocyte infusions support the role of a graft-versus-lymphoma effect. Leukemia. 2012;26(3):520-526.

29. Kanakry JA, Kasamon YL, Gocke CD, et al. Outcomes of related donor HLA-identical or HLA-haploidentical allogeneic blood or marrow transplantation for peripheral T cell lymphoma. Biol Blood Marrow Transplant. 2013;19(4):602-606.

30. Corradini P, Dodero A, Zallio F, et al. Graft-versus-lymphoma effect in relapsed peripheral T-cell non-Hodgkin's lymphomas after reducedintensity conditioning followed by allogeneic transplantation for hematopoietic cells. J Clin Oncol. 2004;22(11):2172-2176.
31. Wulf GG, Hasenkamp J, Jung W, Chapuy B, Truemper L, Glass B. Reduced intensity conditioning and allogeneic stem cell transplantation after salvage therapy integrating alemtuzumab for patients with relapsed peripheral T-cell non-Hodgkin's lymphoma. Bone Marrow Transplant. 2005;36(3):271-273.

32. O'Connor OA, Pro B, Pinter-Brown L, et al. Pralatrexate in patients with relapsed or refractory peripheral T-cell lymphoma: results from the pivotal PROPEL study. J Clin Oncol. 2011;29(9):1182-1189.

33. Coiffier B, Pro B, Prince HM, et al. Results from a pivotal, open-label, phase II study of romidepsin in relapsed or refractory peripheral T-cell lymphoma after prior systemic therapy. J Clin Oncol. 2012;30(6): 631-636.

34. Coiffier B, Pro B, Prince HM, et al. Romidepsin for the treatment of relapsed/refractory peripheral T-cell lymphoma: pivotal study update demonstrates durable responses. J Hematol Oncol. 2014;7(1):11.

35. Pro B, Advani R, Brice P, et al. Brentuximab vedotin (SGN-35) in patients with relapsed or refractory systemic anaplastic large-cell lymphoma: results of a phase II study. J Clin Oncol. 2012;30(18):2190-2196.

36. Dovzhanskiy DI, Arnold SM, Hackert T, et al. Experimental in vivo and in vitro treatment with a new histone deacetylase inhibitor belinostat inhibits the growth of pancreatic cancer. BMC Cancer. 2012;12:226.

37. Piekarz RL, Bates SE. Epigenetic modifiers: basic understanding and clinical development. Clin Cancer Res. 2009;15(12):3918-3926.

38. Steele N, Finn P, Brown R, Plumb JA. Combined inhibition of DNA methylation and histone acetylation enhances gene re-expression and drug sensitivity in vivo. Br J Cancer. 2009;100(5):758-763.

39. Gimsing P. Belinostat: a new broad acting antineoplastic histone deacetylase inhibitor. Expert Opin Investig Drugs. 2009;18:501-508.

40. Steele NL, Plumb JA, Vidal L, et al. A phase 1 pharmacokinetic and pharmacodynamic study of the histone deacetylase inhibitor belinostat in patients with advanced solid tumors. Clin Cancer Res. 2008;14(3):804-810.

41. Gimsing P, Hansen M, Knudsen LM, et al. A phase I clinical trial of the histone deacetylase inhibitor belinostat in patients with advanced hematological neoplasia. Eur J Haematol. 2008;81(3):170-176.

42. Lassen U, Molife LR, Sorensen M, et al. A phase I study of the safety and pharmacokinetics of the histone deacetylase inhibitor belinostat administered in combination with carboplatin and/or paclitaxel in patients with solid tumours. Br J Cancer. 2010;103(1):12-17.

43. Steele NL, Plumb JA, Vidal L, et al. Pharmacokinetic and pharmacodynamic properties of an oral formulation of the histone deacetylase inhibitor belinostat (PXD101). Cancer Chemother Pharmacol. 2011;67(6): 1273-1279.

44. Kelly WK, Yap T, Lee J, et al. A phase I study of oral belinostat (PXD101) in patients with advanced solid tumors [abstract]. J Clin Oncol. 2007;25(Suppl):S18.

45. Zain JM, Foss F, Kelly WK, et al. Final results of a phase I study of oral belinostat (PXD101) in patients with lymphoma [abstract]. J Clin Oncol. 2009;27(Suppl):S14.

46. Foss F, Advani R, Duvic M, et al. A phase II trial of belinostat (PXD101) in patients with relapsed or refractory peripheral or cutaneous T-cell lymphoma. Br J Haematol. 2015;168(6):811-819.

47. O'Connor OA, Masszi T, Savage KJ, et al. Belinostat, a novel panhistone deacetylase inhibitor (HDACi), in relapsed or refractory peripheral T-cell lymphoma (R/R PTCL): results from the BELIEF trial [abstract]. J Clin Oncol. 2013;31(Suppl):S8507.

48. Horwitz S, O'Connor O, Jurczak W, et al. Belinostat in relapsed or refractory peripheral T-cell lymphoma (R/R PTCL) subtype angioimmunoblastic T-cell lymphoma AITL: results from the pivotal BELIEF trial [abstract]. Hematol Oncol. 2013;31(Suppl 1):S147.

49. Reimer P, Chawla S. Long-term complete remission with belinostat in a patient with chemotherapy refractory peripheral T-cell lymphoma. J Hematol Oncol. 2013;6:69. 


\section{Publish your work in this journal}

Cancer Management and Research is an international, peer-reviewed open access journal focusing on cancer research and the optimal use of preventative and integrated treatment interventions to achieve improved outcomes, enhanced survival and quality of life for the cancer patient The journal welcomes original research, clinical \& epidemiological studies, reviews \& evaluations, guidelines, expert opinion \& commentary, case reports \& extended reports. The manuscript management system is completely online and includes a very quick and fair peerreview system, which is all easy to use. Visit http://www.dovepress.com/ testimonials.php to read real quotes from published authors.

Submit your manuscript here: http://www.dovepress.com/cancer-management-and-research-journal 